\title{
WIENER TYPE THEOREMS FOR FOURIER-VILENIKIN SERIES WITH NONNEGATIVE COEFFICIENTS AND SOLID SPACES
}

\section{S. S. VOLOSIVETS}

Abstract. In the present paper we show that $L^{p}$-integrability near zero of a function on Vilenkin group $G$ with nonnegative Fourier-Vilenkin coefficients implies $L^{p}$-integrability on $G$, if $p$ is even integer. This is an analog of N. Wiener-S. Wainger result. A refinement of HausdorffYoung-F. Riesz inequality is obtained and several examples concerning embeddings of solid function spaces on $G$ are given.

Mathematics subject classification (2010): 43A75,43A15.

Keywords and phrases: Vilenkin system, Fourier-Vilenkin coefficients, Hausdorff-Young-F. Riesz inequality, mixed norm, Besov space.

\section{REFERENCES}

[1] J. M. Ash, M. Rains And S. VAGi, Fourier series with positive coefficients, Proc. Amer. Math. Soc., 101, 2 (1987), 392-393.

[2] J. M. Ash, S. Tikhonov And S. J. TUNG, Wiener's positive Fourier coefficients in variants of $L^{p}$ spaces, Michigan Math. J., 59, 1 (2010), 143-151.

[3] N. K. BARI, Trigonometric series, Fizmatgiz, Moskva, 1961 (in Russian). English transl.: N. Bary, A treatise on trigonometric series. V 1,2., Pergamon Press, New York, 1964.

[4] G. F. BACHELIS, On the upper and lower majorant properties in $L^{p}(G)$, Quart. J. Math. Oxford ser. (2), 24, 1 (1973), 119-128.

[5] R. P. BoAs, Entire functions, Academic Press, New York, 1964.

[6] S. FRIDLI, On the rate of convergence of Cesaro means of Walsh-Fourier series, J. Approxim. Theory, 76, 1 (1994), 31-53.

[7] B. I. Golubov, A. V. EFimov And V. A. Skvortsov, Walsh series and transforms, Kluwer, Dordrecht, 1991.

[8] G. H. HaRdy, J. E. LitTlewood, Notes on the theory of series (XIX): A problem concerning majorant of Fourier series, Quart. J. Math. Oxford ser., 6 (1935), 304-315.

[9] J. H. Hedlund, Multipliers of $H^{p}$ spaces, J. Math. Mech., 18, 11 (1969), 1067-1074.

[10] C. N. KellogG, An extension of the Hausdorff-Young theorem, Michigan Math. J., 18, 2 (1971), $121-128$.

[11] H. N. MAZHAR AND S. TIKHONOv, Wiener-type theorems for Jacobi series with nonnegative coefficients, Proc. Amer. Math. Soc., 140, 3 (2012), 977-986.

[12] R. E. A. C. PALey, On Fourier series with positive coefficients, J. London Math. Soc., 7, 3 (1932), 205-208.

[13] H. S. Shapiro, Majorant problems for Fourier coefficients, Quart. J. Math. Oxford ser. (2), 26, 1 (1975), 9-18.

[14] N. YA. Vilenkin, A class of complete orthonormal series (in Russian), Izv. Akad. nauk SSSR. Ser. Mat., 11, 4 (1947), 363-400.

[15] S. S. VOLOSIVETS, On certain conditions in the theory of series with resprect to multiplicative systems (in Russian), Analysis Math., 33, 3 (2007), 227-246.

[16] S. S. Volosivets, Modified Hardy and Hardy-Littlewood operators and their behaviour in various spaces, Izvestiya: Math., 75, 1 (2011), 29-51. 
[17] S. WAInger, A problem of Wiener and the failure of a principle for Fourier series with positive coefficients, Proc. Amer. Math. Soc., 20, 1 (1969), 16-18.

[18] C. WATARI, On generalized Walsh-Fourier series, Tohoku Math. J., 10, 3 (1958), 211-241.

[19] A. Zygmund, Trigonometric series, 2nd ed., Vol. 2., Cambridge Univ. Press, London, 1958. 